\title{
PROJETO DE ENSINO DE ESTATÍSTICA NA FORMAÇÃO INICIAL DE PROFESSORES DE MATEMÁTICA: indícios de saberes disciplinares'
}

\author{
Willian Damin² \\ Guataçara dos Sant os Junior 3 \\ Rudolph dos Santos Gomes Pereira 4
}

\begin{abstract}
RESUMO
O objetivo deste artigo é analisar as contribuições de um Projeto de Ensino de Estatística para o desenv olvimento e/ou manifestação dos saberes disciplinares em um curso de Licenciatura em Matemática. Foi proposto aos 11 (onze) licenciandos participantes, a leitura de textos no campo da Educação Estatística, a realização de tarefas que env olviam conteúdos de Estatística Básica e o desenv olvimento de uma investigação estatística. Com a intenção de alcançar o objetivo, foi adotada uma metodologia de pesquisa de cunho qualitativo e para a coleta de dados utilizou-se memoriais reflexivos, narrativas de aprendizagem e tarefas realizadas pelos licenciandos. A análise de dados pautou-se na teoria da Análise Textual Discursiv a que permitiu realizar interpretações dos registros produzidos. As análises indicam algumas dificuldades, a valorização dos conteúdos de Estatística como campo de ensino e o desenvolvimento das competências estatísticas enquanto saberes disciplinares.
\end{abstract}

Palavras-chave: Projeto de Ensino de Estatística. Educação Estatística. Licenciatura em Matemática.

\section{TEACHING STATISTICS PROJECT IN INITIAL FORMATION OF MATHEMATICS \\ TEACHERS: evidence of diciplinary knowledge}

\begin{abstract}
1 Apoio financeiro: Coordenação de Aperfeiçoamento de Pessoal de Nível Superior (CAPES).

2 Doutor em Ensino de Ciência e Tecnologia pela UTFPR/PG. Docente do curso de Licenciatura em Matemática da UENP/CP. ORCID iD: https://orcid.org/0000-0002-6795-9772 E-mail: wdamin@uenp.edu.br

3 Doutor em Ciências Geodésicas pela UFPR. Docente do Programa de Pós-Graduação em Ensino de Ciência e Tecnologia da UTFPR/PG. ORCID iD: https://orcid.org/0000-0002-62347961 E-mail: guata@utfpr.edu.br

4 Doutor em Educação pela UNESP/PP. Docente do Programa de Pós-Graduação em Ensino da UENP/CP. ORCID iD: https://orcid.org/0000-0003-0504-7329. E-mail: rudolphsantos@uenp.edu.br
\end{abstract}


The purpose of this article is to analyze the contributions of a Statistics Teaching Project for the development and/or manifestation of disciplinary knowledge in an undergraduate mathematics teaching course. The eleven undergraduate students who took part in the study were required to read selected texts from the field of Statistical Education, to do tasks inv olving Basic Statistics content, and to carry out a statistical investigation. Adopting a qualitative approach, data were gathered through reflective memorials, learning narratives and the tasks done by the participants. The analysis of data was based on the Discursive Textual Analysis theory. The analysis indicates some difficulties, the valorization of Statistics contents as a field of teaching and the development of statistical skills as disciplinary knowledge.

Keywords: Statistics Teaching Project. Statistical Education. Undergraduate mathematics teaching course.

\section{PROYECTO DE ENSEÑANZA DE ESTADÍSTICA EN LA FORMACIÓN INICIAL DE PROFESORES DE MATEMÁTICA: indicios de saberes disciplinares}

\section{RESUMEN}

El objetivo de este artículo es analizar las contribuciones de un Proyecto de Enseñanza de Estadística para el desarrollo y/o manifestación de los saberes disciplinares en un curso de Licenciatura en Matemáticas. Se propuso a los 11 (once) licenciantes participantes, la lectura de textos en el campo de la Educación Estadística, la realización de tareas que inv olucra contenidos de Estadística Básica y el desarrollo de una investigación estadística. Con la intención de alcanzar el objetivo, se adoptó una metodología de inv estigación de cuño cualitativo y para la recolección de datos se utilizaron memorias reflexiv as, narrativ as de aprendizaje y tareas realizadas por los licenciandos. El análisis de datos se basó en la teoría del Análisis textual Discursivo que permitió realizar interpretaciones de los registros producidos. Los análisis indican algunas dificultades, la valorización de los contenidos de Estadística como campo de enseñanza y el desarrollo de las competencias estadísticas como saberes disciplinares.

Palabras clave: Proyecto de Enseñanza de Estadística. Educación Estadística. Licenciatura en Matemáticas.

\section{INTRODUÇÃO}

Ao longo dos anos alguns documentos, como a Lei de Diretrizes e Bases da Educação Nacional (LDB) e as Diretrizes Curriculares Nacionais (DCN) propuseram que reformas nas licenciaturas, "estimuladas a transformarem-se na direção de um ensino que quebre a dicotomia entre teoria e prática, privilegie a construção de um saber profissional docente e responda, de modo mais efetivo, aos anseios da sociedade" (COSTA; PAMPLONA, 2011). 
Destaca-se, mais recentemente a Resolução do Conselho Nacional de Educação/Conselho Pleno (CNE/CP 2) de 1 de julho de 2015 que trata das Diretrizes Curriculares Nacionais para a Formação Inicial e Continuada em Nível Superior de Profissionais do Magistério para a Educação Básica. A resolução ressalta a importância da aproximação entre as instituições de formação de professores e a escola de Educação Básica; o repertório de conheciment os e habilidades dos professores para atuação em sala de aula.

A literatura revela que a formação de professores de Matemática que ensinam ou ensinarão Estatística na Educação Básica possui lacunas nos conteúdos a serem explorados e como consequências aparecem às dificuldades com esse tema. Enfatiza-se que os saberes disciplinares influenciam na metodologia adotada pelo professor em sala de aula (MIZUKAMl et al., 2002), na decisão sobre os conteúdos de ensino, na contribuição para a aprendizagem e que eles compõem a base do ofício docente.

Entende-se que em um curso de formação inicial de professores os diferentes saberes podem ser articulados pelo professor formador por meio de um trabalho que faça sentido, com discussões e reflexões sobre o ensino dos conhecimentos específicos, contribuindo para a formação do licenciando de modo que ele possa utilizar os conhecimentos adquiridos em sala de aula.

É nessa perspectiva de formação de professores que foi ofertado um projeto de ensino voltado para o campo da Educação Estatística, na intenção de contribuir com os saberes docentes dos licenciandos e consequentemente com a sua prática docente em sala de aula. A pesquisa faz parte do Projeto de Pesquisa "O Ensino e Aprendizagem de Probabilidade e Estatística", coordenado pelo Profo Dr. Guataçara dos Santos Junior, do Programa de Pós-Graduação em Ensino de Ciência e Tecnologia (PPGECT) da Universidade Tecnológica Federal do Paraná, campus de Ponta Grossa (UTFPR/PG).

Por se tratar de um recorte de uma pesquisa de doutorado (DAMIN, 2018), apresenta-se neste artigo a análise das contribuições de um Projeto 
de Ensino de Estatística (PEE) para o desenvolvimento e/ou manifestação dos saberes disciplinares em um curso de Licenciatura em Matemática de uma universidade pública do norte do estado do Paraná.

\section{REFERENCIAL TEÓRICO}

A constituição dos saberes docentes se dá continuamente, desde a formação inicial, e se estende durante toda a trajetória de vida do professor. Estar em formação é construir maneiras de ser e estar na profissão, adquirir uma identidade profissional, que vem do querer do professor, contudo, é de responsabilidade das universidades que ofertam cursos de Licenciaturas e do compromisso das políticas públicas. A formação inicial "deve promover a construção dos saberes docentes de maneira que estes relacionem os já validados cientificamente aos que estão em processo de construção por parte do professor, articulando o conhecimento adquirido na formação com a sua experiência de vida e profissional" (ALBUQUERQUE; GONTIJO, 2013, p. 79).

Em Tardif (2014), percebe-se uma perspectiva de formação docente que visa articular, diferentes saberes, como os saberes da formação profissional que incluem os saberes das Ciências da Educação e da ideologia pedagógica; os saberes disciplinares; os saberes curriculares e os saberes experienciais.

A prática docente incorpora saberes sociais definidos e selecionados pela instituição universitária, integrados sob a forma de disciplinas, chamados de saberes disciplinares. Esses saberes são aqueles que pertencem a diferentes campos do conhecimento (ciências exatas, ciências biológicas, linguagem, entre outros), extraídos pelos professores para serem ensinados, porém não são produzidos por eles (TARDIF, 2014). Exige, portanto, conhecimento e domínio do conteúdo a ser ensinado.

Segundo Tardif (2014) esses saberes são historicamente produzidos e acumulados pela sociedade, são geridos pela comunidade científica no qual o acesso a eles são definidos e selecionados por meio de instituições educacionais. 
A junção dos saberes da formação profissional, dos saberes disciplinares, dos saberes curriculares e dos experienciais resulta em um único saber específico, que se fundamenta e se legitima na atuação docente cotidiana, chamado de saber profissional. Portanto, para Tardif (2014), o saber profissional é um "saber plural, formado pelo amálgama, mais ou menos coerente, de saberes oriundos da formação profissional e de saberes disciplinares, curriculares e experienciais" (TARDIF, 2014, p. 36).

Ao considerar os saberes necessários para a docência, cita-se o desenvolvimento das competências estatísticas, letramento, pensamento e raciocínio estatístico, como parte constituinte dos saberes disciplinares, pois, eles não se restringem ao conhecimento de teorias e leis, mas incluem também as noções epistemológicas, os fundamentos e as perspectivas vinculadas a atividade docente (CARVALHO, GIL PÉREZ, 2006).

Ser letrado estatisticamente é saber utilizar os conhecimentos estatísticos em diversas situações, entender fenômenos de relevância social e pessoal, tais como: as taxas de criminalidade, o crescimento populacional, o aproveitamento educacional, dentre outros contextos que aparecem no cotidiano que merecem ser interpretados e, posteriormente, modificados (GAL, 2002).

O modelo de Letramento Estatístico proposto por Gal (2002) é composto de elementos cognitivos que permitem ao indivíduo compreender, interpretar e avaliar criticamente informações estatísticas, e por dois elementos de disposição, responsáveis pela postura ativa diante da informação estatística, que são as crenças e atitudes e a postura crítica.

Os elementos cognitivos são: 1) a alfabetização estatística, isto é, a capacidade de ler informações textuais, em gráficos e tabelas; 2) os conhecimentos estatísticos; 3) os conhecimentos matemáticos; 4) o conhecimento do contexto; 5) e a competência para elaborar questões críticas.

Para a compreensão e interpretação de informações estatísticas é necessário o conhecimento de conceitos e procedimentos básicos de Estatística e Probabilidade (GAL, 2002). O autor ainda propõe cinco tópicos 
dos conhecimentos básicos de Probabilidade e Estatística, assim descritos: a) a necessidade dos dados e a maneira como são coletados; b) a familiaridade com os termos e ideias básicas relacionadas à Estatística Descritiva; c) a familiaridade com os termos e ideias básicas relacionadas às apresentações gráficas e tabulares; d) a compreensão das noções básicas de Probabilidade; e) o conhecimento sobre como as conclusões e inferências estatísticas são obtidas.

A partir dessas noções básicas de Estatística, Gal (2002) salienta outros aspectos que considera importantes para 0 desenvolvimento do conhecimento estatístico. O primeiro é o conhecimento das ideias-chave da investigação estatística, e a primeira delas é a existência da variabilidade ${ }^{5}$. O segundo aspecto é a compreensão de que a média aritmética e a mediana são meios para resumir um conjunto de dados a partir de sua medida de tendência central e que a média é mais afetada do que a mediana. Um terceiro aspecto é o entendimento de que o mesmo conjunto de dados pode ser representado na forma de gráficos ou como tabelas. $O$ quarto aspecto é o conhecimento do significado de eventos aleatórios, ou ao acaso.

Tardif (2014) destaca a transmissão da matéria como uma condicionante que está relacionada com o ensino do conteúdo e com a aprendizagem dos alunos. Sinaliza-se aqui o saber disciplinar necessário para a prática pedagógica, que pode ser entendido no contexto da Estatística, como por exemplo, a capacidade do docente em reconhecer o processo desenvolvido pelo aluno em uma determinada tarefa estatística, como na construção de gráficos e tabelas ou no entendimento da variação.

Para ser letrado estatisticamente, Gal (2002) destaca a importância dos conhecimentos matemáticos, que permitem a utilização de forma correta dos objetos estatísticos. Por exemplo, para se calcular a média de um conjunto de dados é necessário conhecimento sobre soma e divisão de números racionais. Essa colocação do autor ressalta a importância da

5 O termo variabilidade refere-se à característica da entidade observável, na qual a variação descreve ou mede essa característica (SILVA, 2007). 
articulação entre o conceito e o procedimento no processo de construção do conhecimento estatístico.

Além do conhecimento de tópicos matemáticos e estatísticos, é necessário também o conhecimento do contexto.

O conhecimento do contexto é o principal determinante da familiaridade do leitor com fontes para a variação e erro. Se um ouvinte ou leitor não está familiarizado com um contexto em que os dados foram coletados, torna-se mais difícil de imaginar porque pode ocorrer uma diferença entre os grupos, o que interpretações alternativas podem existir para os resultados encontrados sobre uma associação detectada entre certas variáveis, ou como um estudo poderia dar errado (GAL, 2002, p. 15).

De acordo com Silva (2007), o conceito de variabilidade pode ser construído na relação entre a leitura de informações estatísticas e a compreensão do contexto. Desta forma, o conhecimento do contexto é parte fundamental no letramento estatístico, pois, pode permitir compreender os dados e sua história.

O quinto e último elemento cognitivo do modelo de letramento estatístico é a criticidade. Na perspectiva de Gal (2002), a habilidade para elaborar questões críticas ou analisar criticamente uma informação é extremamente importante, na medida em que não deixam o consumidor refém de informações estatísticas.

Para complementar os cinco elementos cognitivos já apresentados, Gal (2002) propõe ainda a existência de dois elementos de disposição, a saber, a postura crítica; e as crenças e atitudes ${ }^{6}$.

A postura crítica é a propensão de um adulto ter um comportamento questionador diante de informações quantitativas que podem ser unilaterais, viesadas ou incompletas, seja de maneira intencional ou não. Quanto às crenças e atitudes, se um indivíduo acredita ser capaz de interpretar informações estatísticas (crença) e tem uma atitude positiva em relação a investigação estatística, ele tende a apresentar uma postura crítica em relação às informações estatísticas (SILVA, 2007, p. 25-26).

\footnotetext{
${ }_{6}$ Atitude é a prontidão de uma pessoa para responder a determinado objeto de maneira favorável ou desfavorável. Silva (2000) dedica uma dissertação que envolve o estudo de atitudes de alunos de graduação em relação à Estatística.
}

Revista Exitus, Santarém/PA, Vol. 9, №3, P. 309 - 338, JUL/SET 2019. 
Outra competência, o pensamento estatístico, pode ser definido como o processo que reconhece a presença da variação em tudo o que se faz com os seguintes elementos: o reconhecimento da variação presente em todo o processo, a necessidade dos dados para medir a variação e o uso de métodos e as ferramentas estatísticas para quantificar e entender a variação, permitindo a tomada de decisões (SNEE, 1990).

Wild e Pfannkuch (1999) ampliaram a definição de pensamento estatístico e apresentam uma estrutura de quatro dimensões: Dimensão 1: 0 ciclo investigativo; Dimensão 2: tipos de pensamento; Dimensão 3: o ciclo interrogativo; e Dimensão 4: disposições.

Segundo Wild e Pfannkuch (1999), o ciclo investigativo refere-se à forma de como se age e pensa durante uma investigação estatística e tem o objetivo de resolver um problema real, geralmente com a intenção de mudar um sistema para melhorar alguma coisa. Nessa primeira dimensão, o conhecimento de onde os alunos podem encontrar problemas, a capacidade de incentivá-los a pensar sobre cada fase da investigação e considerar a forma como as fases estão interligadas são exemplos de conhecimentos estatísticos necessários para o ensino (BURGESS, 2007), entendidos como saber da formação profissional, articulação das ciências da educação com os saberes pedagógicos, baseado em Tardif (2014).

A segunda dimensão de Wild e Pfannkuch (1999) é denominada de tipos de pensamento e envolve o pensamento geral e o pensamento fundamental.

O pensamento geral refere-se ao planejamento do ciclo investigativo e significa decidir o que fazer; como fazer; o que já se conhece do assunto; materiais necessários; os conceitos estatísticos do problema. Pois, todas essas informações influenciam na forma de coletar e analisar os dados (SILVA, 2007).

Wild e Pfannkuch (1999) destacam que o pensamento fundamental é o reconhecimento da necessidade de dados, isto é, a transnumeração, a consideração da variação a partir da tomada de decisão em situações de incerteza, o uso de modelos estatísticos e a contextualização da estatística. 
Coutinho, Silva e Almouloud (2011) entendem que o processo de transnumeração é o trabalho de transformar dados brutos em registro tabular como gráficos e histogramas. Os autores ainda complementam em relação às outras etapas no desenvolvimento do pensamento estatístico.

Quanto ao desenvolvimento do raciocínio com modelos estatísticos, ocorre, particularmente, pela análise da forma, da dispersão e das medidas estatísticas, na busca da construção de uma linguagem própria. Finalmente, a consideração da variação é realizada pela análise da forma (como no item anterior), dispersão e medidas, isto é, usam-se os mesmos objetos para identificar propriedades distintas tais como simetria e amplitude (COUTINHO; SILVA; ALMOULOUD, 2011, p. 501).

A capacidade de planejar uma sequência de ensino adequada, relacionada com a transnumeração, a variação, os modelos estatísticos e a contextualização da estatística, de forma a levar o aluno a compreender a necessidade dos dados podem ser entendidos como um saber da formação profissional, pois, de acordo com Tardif (2014), os saberes relacionados às técnicas e métodos de ensino estão inseridos nesse tipo de saber.

Para Burgess (2007), avaliar as explicações dos alunos, a fim de que compreendam a possível generalização de um conjunto de dados para um grupo maior se caracteriza como um conhecimento do conteúdo sobre variação, o que, com base em Tardif (2014) pode ser entendido como um saber disciplinar. Observa-se a necessidade em desenvolver esse tipo de saber, ao passo que, deve estar presente em um processo de formação docente, como defendido por Tardif (2014).

A terceira dimensão, denominada de ciclo interrogativo, é um processo em uso constante na resolução de problemas estatísticos e diz respeito aos questionamentos macro e micro que são delineados pelo pensador enquanto resolve o problema.

Nesse ciclo, o pensador produz possibilidades, que podem ser de cunho contextual, dos dados ou estatístico, busca informação e idéias, para posteriormente interpretar o resultado estatístico, checa a informação obtida com uma referência interna (o que conhecia) e externa (literatura, outras pessoas, etc), para tomar a decisão sobre o que deve ser mantido, continuado a pesquisar (SILVA, 2007, p. 30). 
O ciclo interrogativo envolve tomar decisões, na busca da interpretação dos resultados, aspecto fundamental em uma investigação estatística, exercendo sua capacidade de analisar do ponto de vista da Estatística, como as visões limitadas de seus alunos podem causar impacto nas interpretações e respostas às questões iniciais (BURGESS, 2007).

A quarta dimensão, denominada de disposições, pode ser entendida como as qualidades pessoais, isto é, o compromisso com ir além com o problema. Algumas dessas qualidades é a curiosidade em querer investigar mais; a imaginação em procurar enxergar o problema sob diferentes perspectivas; ceticismo com as conclusões alcançadas e se elas são justas; entendimento sob a ideia observada.

A partir dessas definições, "pode-se entender o pensamento estatístico como as estratégias mentais utilizadas pelo indivíduo para tomar decisão em toda a etapa de um ciclo investigativo" (SILVA, 2007, p. 30).

Silva (2007) ainda ressalta que em uma pesquisa, mesmo que de forma inconsciente, o pensamento estatístico está sendo utilizado. Assim, quanto mais uma disciplina estimular o pensamento estatístico, o letramento estatístico também será desenvolvido.

A terceira competência estatística é o raciocínio estatístico, definido por Garfield (2002) como a maneira com a qual uma pessoa raciocina com ideias e informações estatísticas, que envolve interpretações sobre dados, gráficos e tabelas. Silva (2007) relata que para uma pessoa desenvolver o raciocínio estatístico, é necessário que o ensino proporcione situações de decisão ao aluno, oferecendo a ele condições de avaliar suas opções de escolha.

Pode-se dizer que uma pessoa racional em Estatística é aquela que consegue decidir, baseada em observação de dados, qual a melhor estratégia a seguir em uma determinada situação de incerteza. "Significa, ainda, entender e ser capaz de explicar um processo estatístico, e ter a capacidade de interpretar, por completo, os resultados de um problema baseado em dados reais" (CAMPOS et al., 2011, p. 481).

Garfield (2002) foca em alguns tipos corretos de raciocínio estatístico: 
a) raciocínio sobre dados: reconhecer ou categorizar os dados e entender as formas de representações.

b) raciocínio sobre representação dos dados: compreender como os gráficos podem ser modificados para representar melhor um conjunto de dados.

c) raciocínio sobre medidas estatísticas: entender o que representa as medidas de tendência central e qual medida é a mais adequada em cada caso.

d) raciocínio sobre incerteza: usar adequadamente ideias de aleatoriedade e probabilidade para fazer julgamentos sobre eventos que envolvem incerteza.

e) raciocínio sobre amostras: entender a relação entre a amostra e a população, fazendo-se cético com inferências a partir de pequenas amostras.

f) raciocínio sobre associação: entender como julgar e interpretar a relação entre duas variáveis, interpretar uma tabela de dupla entrada. Entender que uma forte correlação entre duas variáveis não significa que uma cause a outra.

\section{ASPECTOS METODOLÓGICOS}

Esta pesquisa envolve uma metodologia de pesquisa qualitativa no que se refere à abordagem do problema, uma vez que o pesquisador buscou coletar e analisar os dados que permitiram investigar as contribuições da oferta de um Projeto de Ensino de Estatística na formação inicial de professores de Matemática para $\bigcirc$ desenvolvimento dos saberes disciplinares. Sobre pesquisas qualitativas, destaca-se que sua principal característica é ser compreensiva ou interpretativa. Desta forma, no processo de pesquisa, a utilização da abordagem qualitativa, induz à busca da compreensão das percepções pessoais dos participantes (ALVESMAZZOTTI, GEWANDSZNAJDER, 1999). 
Os principais instrumentos de coleta de dados durante a aplicação do PEE foram as tarefas desenvolvidas pelo pesquisador e respondidas pelos participantes, o memorial reflexivo e as narrativas de aprendizagem.

O PEE, com carga horária de 36 horas/aulas, foi ofertado na modalidade presencial, para a contribuição da formação inicial de professores de Matemática em uma universidade pública do norte do estado do Paraná, Brasil. Participaram do projeto 11 (onze) licenciandos, matriculados no quarto ano do curso.

O PEE foi composto de tarefas de Estatística básica, de leituras de artigos sobre Educação Estatística e de um projeto de Investigação Estatística. Algumas das tarefas propostas eram contextualizadas e para a sua resolução foi necessário conhecimentos matemáticos e estatísticos pertencentes ao currículo da Educação Básica conforme previsto por Paraná (2008). No quadro a seguir relaciona-se o título de cada uma das tarefas selecionadas para o PEE.

Quadro 1 - Tarefas realizadas no PEE

\begin{tabular}{|c|c|}
\hline NÚMERO & TAREFAS \\
\hline 1 & Perfil da turma (ESTEVAM, 2015) \\
\hline 2 & O Homem Vitruviano (SILVA; CAZORLA; MAGINA, 2012) $^{\text {Simulação de um dado equilibrado7 (IME-USP) }}$ \\
\hline 3 & Simotas de uma turma \\
\hline 4 & O Jogo dos 3Ms (LOPES; CORRAL; RESENDE, 2011) \\
\hline 5 & Pesagem de um objeto (ALMEIDA, 2010) \\
\hline 6 & Quantos peixes têm em uma lagoa? (CORDANI, 2004) \\
\hline 7
\end{tabular}

Foram propostas tarefas de Estatística Básica, de forma a atender os conteúdos descritos nas DCE (PARANÁ, 2008), que incluem pesquisa estatística, leitura e interpretação de gráficos e tabelas, medidas de tendência central, população, amostra e probabilidade. A estrutura do PEE também possibilitou o desenvolvimento de um projeto de Investigação

\footnotetext{
7 Disponível em:

https://www.ime.usp.br/images/arquivos/imagens/ativestat/PL02_detalhes_dado_equilibrad o.pdf
} 
Estatística e as suas fases de acordo como Martins e Ponte (2011). A intenção foi a de oportunizar aos licenciandos discussões para desenvolvimento do conhecimento de como ensinar investigação estatística ao fazer uso da própria investigação.

Ao elaborar O PEE procurou-se coerência com os conhecimentos necessários para atuação na Educação Básica de forma que as tarefas elaboradas pudessem contribuir para os saberes para a docência. Assim, entende-se que as atividades desenvolvidas podem contribuir para a formação inicial do professor.

Os textos escolhidos foram publicados por periódicos qualificados na área de Ensino pela CAPES e selecionados de acordo com os objet ivos do $\mathrm{PEE}$, isto é, possibilitar a apropriação de aspectos teóricos em relação à Educação Estatística pelos licenciandos.

Quadro 2 - Artigos escolhidos para leitura na disciplina

\begin{tabular}{|c|c|c|c|}
\hline ARTIGos & AUTORES & ANO & $\begin{array}{c}\text { LOCAL DE } \\
\text { PUBLICAÇÃO }\end{array}$ \\
\hline $\begin{array}{c}\text { O Ensino de Estatística e da Probabilidade } \\
\text { na Educação Básica e a Formação de } \\
\text { Professores }\end{array}$ & Celi Espasandin Lopes & 2008 & $\begin{array}{c}\text { Caderno } \\
\text { Cedes }\end{array}$ \\
\hline $\begin{array}{c}\text { Educação Estatística no Contexto da } \\
\text { Educação Crítica }\end{array}$ & $\begin{array}{c}\text { Celso Ribeiro Campos } \\
\text { Otávio Roberto Jacobini } \\
\text { Maria Lucia L. Wodewotzki } \\
\text { Denise H. L. Ferreira }\end{array}$ & 2011 & Bolema \\
\hline $\begin{array}{c}\text { A interpretação de medidas de } \\
\text { tendência central de futuros professores e } \\
\text { educadores na realização de uma } \\
\text { investigação estatística }\end{array}$ & $\begin{array}{c}\text { Raquel Santos } \\
\text { João Pedro da Ponte }\end{array}$ & 2012 & $\begin{array}{c}\text { Atas XXIII } \\
\text { SIEM }\end{array}$ \\
\hline $\begin{array}{c}\text { O Letramento Presente na Construção de } \\
\text { Tabelas por Alunos da Educação de } \\
\text { Jovens e Adultos }\end{array}$ & $\begin{array}{c}\text { Keli Cristina Conti } \\
\text { Dione Lucchesi de Carvalho }\end{array}$ & 2011 & Bolema \\
\hline $\begin{array}{c}\text { Sequência de ensino contemplando a } \\
\text { estatística nos anos finais do ensino } \\
\text { fundamental segundo pressupostos da } \\
\text { contextualização }\end{array}$ & $\begin{array}{c}\text { Danieli Walichinski } \\
\text { Guataça dos Santos } \\
\text { Junior }\end{array}$ & 2012 & Repositório \\
UTFPR
\end{tabular}

Fonte: Autores

A escolha dos textos para compor o PEE ocorreu em função da necessidade de referência ao respaldo teórico, tendo em vista a sua importância em um curso de formação inicial de professores, pois a teoria é indissociável da prática. Assim, os textos foram intercalados com as tarefas. 
Para a organização dos dados, os licenciandos e os instrumentos de coleta de dados foram decodificados com os seguintes indicadores simbólicos dispostos no Quadro 3.

Quadro 3 - Decodificação

\begin{tabular}{|c|c|}
\hline DESCRIÇÃO & INDICADORES SIMBÓLICOS \\
\hline Licenciandos & $\mathrm{L} 1, \mathrm{~L} 2, \ldots, \mathrm{L} 11$ \\
\hline Memoriais reflexivos & $\mathrm{Ml}, \mathrm{M} 2$ e M3 \\
\hline Narrativas de aprendizagem & $\mathrm{N} 1, \mathrm{~N} 2, \ldots, \mathrm{N} 18$ \\
\hline Tarefas & $\mathrm{T} 1, \mathrm{~T} 2, \ldots, \mathrm{T} 7$ \\
\hline
\end{tabular}

Fonte: Autores

O PEE foi construído considerando suas potencialidades para a formação de professores de Matemática que ensinarão Estatística na Educação Básica, de forma a manifestar e/ou desenvolver saberes docentes com a: a) apropriação de conhecimentos teóricos sobre de Estatística e o desenvolvimento dos saberes; b) interação dos licenciandos nas discussões realizadas sobre os textos, em relação à utilização da Estatística em sala de aula e a sua importância no contexto da Educação Matemática (LOPES, 1998, 2003; CAMPOS et al., 2011); c) articulação entre conhecimento teórico e prático (BRASIL, 2001b, 2015; PARANÁ, 2008; TARDIF, 2014); d) possibilidade de reflexão sobre a prática em sala de aula (ROLDÃO, 2007; TARDIF, 2014).

Frente ao objetivo de investigar as contribuições da oferta de um Projeto de Ensino de Estatística na formação inicial de professores de Matemática para o desenvolvimento das competências estatísticas e com base nos registros coletados, optou-se pelo uso da metodologia de Análise Textual Discursiva, tendo em vista que ela surge "[...] como uma nova opção de análise para pesquisas de natureza qualitativa e de caráter hermenêutico" (MORAES; GALIAZZI, 2007, p. 140).

A escolha por essa metodologia de análise permitiu a interpretação e compreensão das reflexões realizadas pelos participantes da pesquisa ao desenvolverem o memorial descritivo e as narrativas de aprendizagem, pois,

na análise textual discursiva, o texto (propriamente dito) é considerado um meio de expressão do sujeito, de modo que, ao seu analista, cabe classificá-lo em unidades contendo frases ou palavras 
repetidas, de forma a inferir uma expressão que as representem (LUCCAS, 2011, p. 198).

Antes de iniciar a análise do corpus (conjunto de dados coletados e submetidos aos procedimentos analíticos) definiu-se a priori a categoria da estrutura da análise dos dados que emergiu da perspectiva teórica escolhida para esta tese, isto é, os saberes docentes. A categoria e as subcategorias de análise foram elaboradas a partir do referencial teórico sobre saberes docentes, e as unidades de análise emergiram a partir da leitura e reflexão dos dados coletados.

\section{RESULTADOS E DISCUSSÕES}

Para a interpretação dos dados, foi considerado os "Saberes docentes" como uma categoria de análise que em seguida foi dividida em subcategorias. Apresenta-se aqui a subcategoria "Saberes disciplinares", com duas unidades de análise, a saber, "Dificuldades/Importância/Motivos/Razões para ensinar Estatística" e "Competências estatísticas". Essas unidades de análise foram emergentes, porém para o exercício da docência, se tornam complementares, onde a primeira é necessária apenas ao professor e a segunda pode ser relacionada com qualquer indíviduo com formação estatística.

A subcategoria "Saberes disciplinares" exige organização, conhecimento e domínio do conteúdo a ser ensinado. Para isso, faz-se necessário que o professor entenda a importância do conteúdo para a disciplina e compreenda os motivos e as razões para ensinar.

O Quadro 4 apresenta alguns excertos coletados com diferentes instrumentos (narratovas de aprendizagem, tarefas de estatística e memorial reflexivo) elaborados pelos licenciandos durante a realização do Projeto de Ensino de Estatística.

Quadro 4 - Subcategoria "Saberes disciplinares"

\begin{tabular}{|c|l|}
\hline $\begin{array}{c}\text { Unidade } \\
\begin{array}{c}\text { Motivos/Rades/Importância/ } \\
\text { ensinar Estatística }\end{array}\end{array}$ & $\begin{array}{l}\text { Não dava pra calcular a média da cor dos olhos e do gênero, } \\
\text { por serem variáveis qualitativas. Somente dava para calcular a } \\
\text { média de variáveis quantitativas que foi o caso da altura e do } \\
\text { peso (L8N4). }\end{array}$ \\
\hline
\end{tabular}




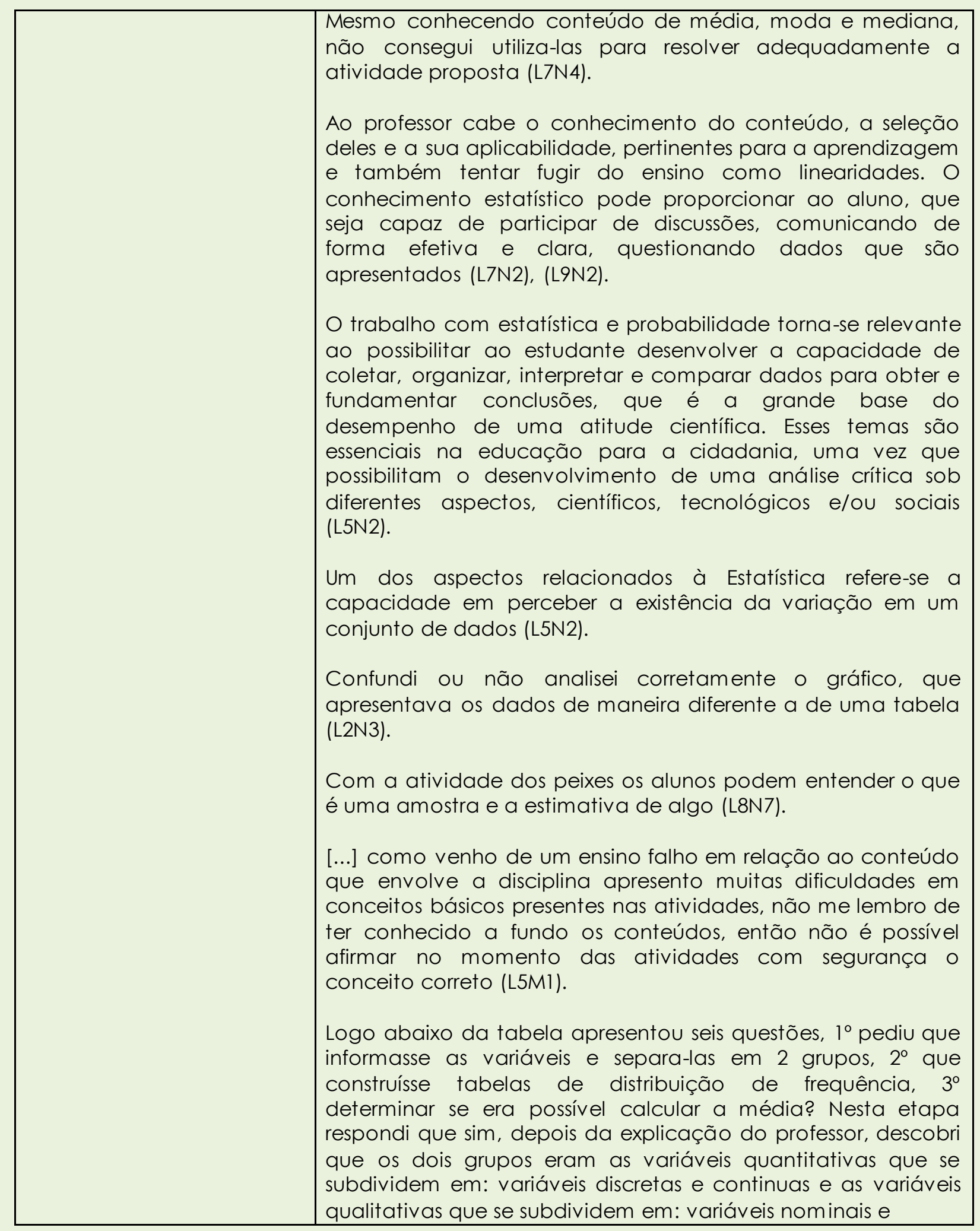

\begin{tabular}{|c|l|}
\hline $\begin{array}{c}\text { Unidade } \\
\text { Competências estatísticas }\end{array}$ & ordinais (A7MI), (L4N4). \\
& $\begin{array}{l}\text { Na estimativa populacional tivemos uma experiência com a } \\
\text { quantidade de peixes em um rio. Retirávamos amostras, } \\
\text { marcávamos os peixes e devolvíamos no pacote, assim, } \\
\text { encontrando uma estimativa para a quantidade (L4N7). Essa }\end{array}$ \\
\hline
\end{tabular}

Revista Exitus, Santarém/PA, Vol. 9, № 3, p. 309 - 338, JUL/SET 2019. 


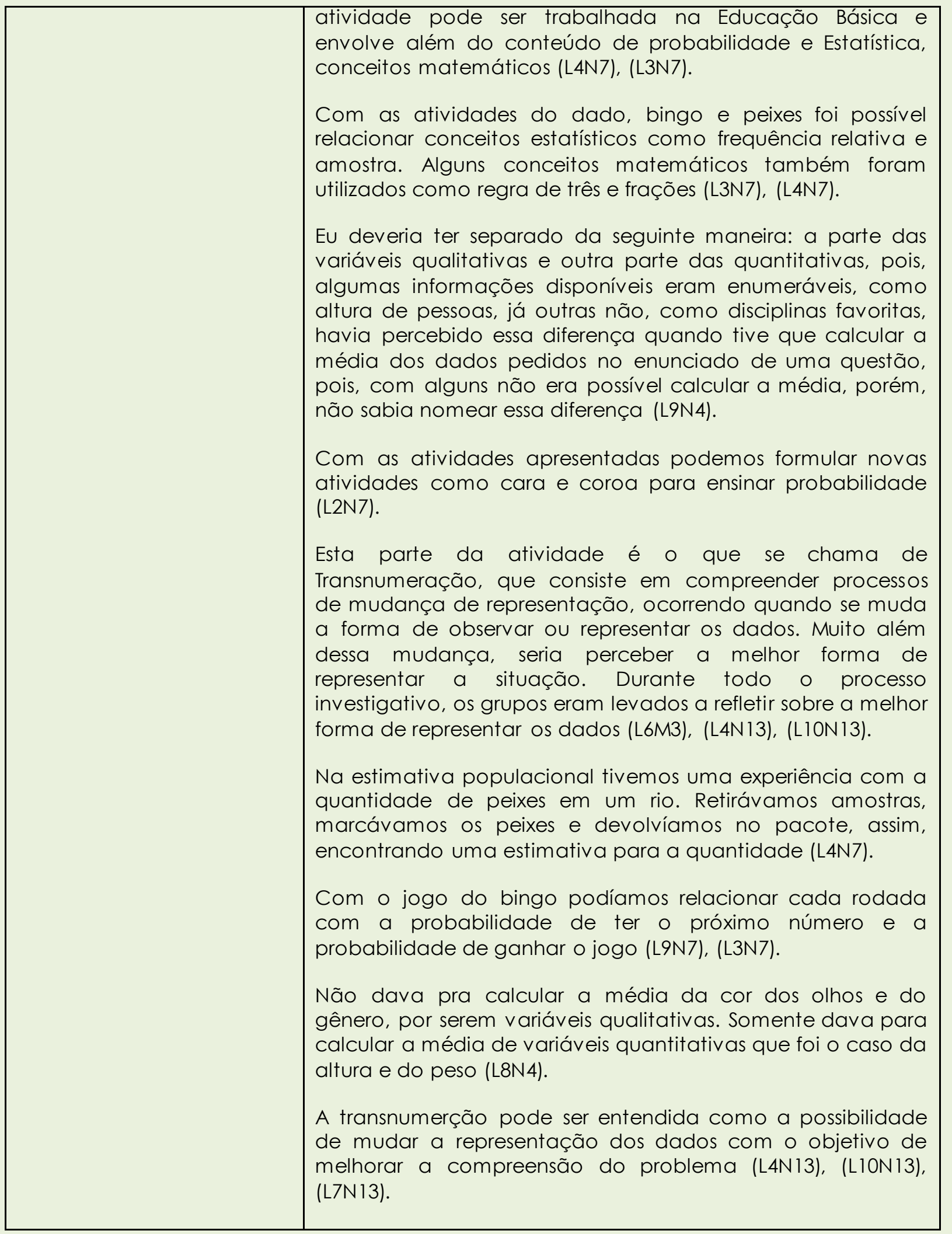

Continua...

\section{Competências estatísticas}

Os dados coletados podem ser representados por meio de gráficos, tabelas, quadros e pictogrmas (L6N13), (L7N13), (L5N 13).

Minha visão sobre estatística era apenas de aplicar os dados e fórmulas e calcular o que se pedia no exercício, porém hoje 


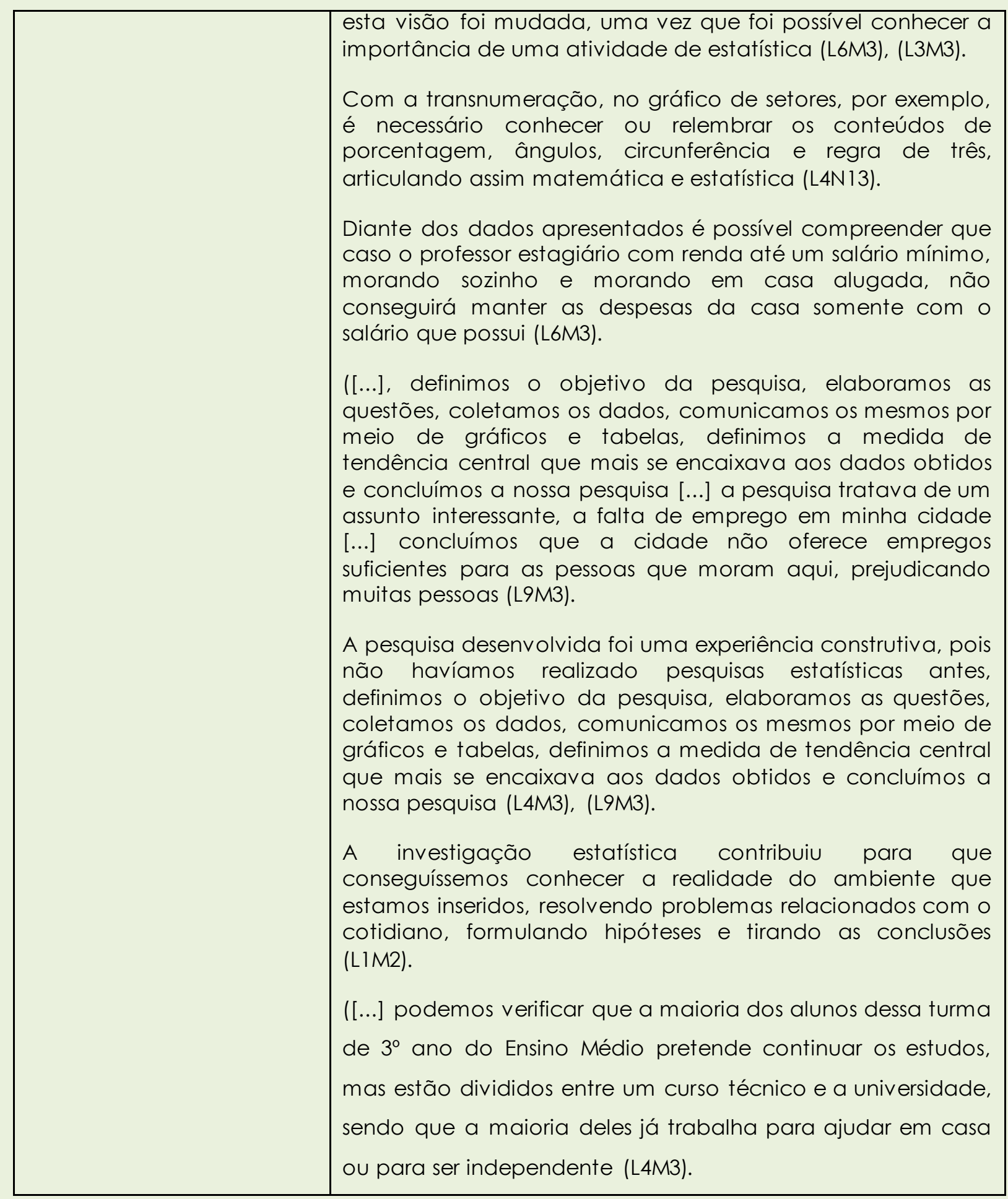

Fonte: Autores

Na unidade "Dificudades/Importância/Motivos/Razões para ensinar Estatística", alguns licenciandos tiveram dificuldades em determinadas atividades, como por exemplo, reconhecer os dados como variáveis qualitativas ou quantitativas e até mesmo na interpretação de gráficos, 
conforme relata L2N3 (Confundi ou não analisei corret amente o gráfico, que apresentava os dados de maneira diferente a de uma tabela).

Outros licenciandos afirmaram conhecer conceitos, mas não conseguiram articular seu conhecimento para a resolução da atividade, como L7N4 (mesmo conhecendo conteúdo de média, moda e mediana, não consegui utilizá-las para resolver adequadamente a atividade proposta).

Conforme os relatos de L3N7 é possível identificar a manifestação e o desenvolvimento dos saberes disciplinares (Com as atividades do dado, bingo e peixes foi possivel relacionar conceitos est at íst icos como frequência relativa e amostra. Alguns conceit os mat emáticos também foram ut ilizados como regra de três e frações). Ainda, relacionar tais saberes para atuação na Educação Básica, como aponta L8N7 (Com a atividade dos peixes os alunos podem entender o que é uma amostra e a estimativa de algo).

É possível destacar com base nos excertos dos licenciandos, a apropriação de conceitos estatísticos, a importância da Estatística e os motivos para ensiná-la, favorecendo o desenvolvimento dos saberes para a docência.

Um dos aspectos relacionados à Estatística refere-se à capacidade em perceber a existência da variação em um conjunto de dados (L5N2).

O trabalho com est atística e probabilidade torna-se relevante ao possibilit ar ao est udante desenvolver a capacidade de colet ar, organizar, interpret ar e comparar dados para obter e fundamentar conclusões, que é a grande base do desempenho de uma atitude científica. Esses temas são essenciais na educação, para a cidadania, uma vez que possibilitam o desenvolvimento de uma análise crítica sob diferentes aspectos, científicos, tecnológicos e/ou sociais (L5N2).

A articulação desses conteúdos com o cotidiano dos alunos possibilita que eles sejam capazes de interpretarem dados presentes em gráficos e tabelas, além de se tornarem pessoas mais críticas e difíceis de serem manipuladas por notícias da mídia. [...] podemos perceber que os conteúdos estatísticos podem ser articulados de diferentes formas com situações oriundas do cotidiano dos alunos, basta o professor procurar diferentes atividades e adapta-las a sua realidade escolar (L4MI). 
Alguns dos motivos para ensinar Estatística: desenvolver habilidades interpretativas de argumenção, reflexão e criticidade; desenvolver habilidades para a comunicação estatística, usando corretamente a sua terminologia (L5MI).

Os conteúdos de Estatística e Probabilidade desenvolvidos a partir das atividades pensadas contemplam o movimento do pensamento crítico, o que potencializou a formação dos licenciandos, uma vez que a pesquisa envolveu um contexto de particularidades, como a leitura de textos e a discussão das tarefas propostas. De acordo com Costa e Nacarato (2011) essa forma que foi adotada para ensinar Estatística e proporcionar reflexões sobre o campo da Educação Estatística no curso de Licenciatura em Matemática não é uma realidade brasileira, o que sugere a contribuição específica para a formação do futuro professor. Assim,

- desenvolvimento da capacidade crítica de compreensão estatística dos alunos é facilitado pela orientação dos professores e, para isso, é necessário que estes, em sala de aula, tenham plena consciência da importância, em particular, dos conteúdos de Estatística nessa formação crítica do aluno e de sua própria capacidade de lidar com incertezas e aproximações. Além disso, é fundamental que 0 professor tenha um repertório de saberes docentes disciplinares, pedagógicos da disciplina e curriculares, para trabalhar os principais conceitos ligados à Probabilidade e à Estatística (COSTA; NACARATO, 2011, p. 383).

Entende-se que somente os saberes disciplinares não podem proporcionar o sucesso da aprendizagem dos alunos, e, no processo de ensino e aprendizagem torna-se necessário, mas não suficiente (MIZUKAMI, 2004). "No entanto, o professor necessita dominar o conteúdo para ensiná-lo, uma vez que a ausência desse conhecimento faz com que os professores tornem-se inseguros e usem demasiadamente a aula expositiva" (PEREIRA, 2015, p. 132-133). Os excertos colaboram para uma visão diferenciada dessa abordagem tecnicista, o que aponta para a contribuição do PEE para a formação dos licenciandos participantes, tendo em vista a interferência dos saberes disciplinares na elaboração e execução de um planejamento didático. 
As narrativas (entregue em todas as aulas) e os memoriais (entregue a cada seis aulas), ao proporcionarem a exposição do desenvolvimento e/ou manifestação dos saberes docentes, mostram os participantes constitutivos de seu saber, no entanto, também realçam a carência dos cursos de formação e manifestam a necessidade de aprofundamento em seus conhecimentos específicos e teóricos (como venho de um ensino falho em relação ao cont eúdo que envolve a disciplina apresento muitas dificuldades em conceitos básicos presentes nas atividades, não me lembro de ter conhecido a fundo os conteúdos, L5M1). Essa colocação pode ser um dos motivos que leva os professores a trabalharem com a Estatística de forma mecânica, com a valorização das técnicas e dos cálculos (SOUZA, 2013).

Na tentativa de romper com essa visão tecnicista e atender o que é disposto nos documentos oficias que regem a formação de professores, no que concerne aos saberes da disciplina, o excerto abaixo mostra que os licenciandos passaram a compreender a Estatística, objeto de sua atuação didática, com razoável profundidade, visando um fazer pedagógico eficaz para a aprendizagem dos alunos (BRASIL, 2001 a).

Ao professor cabe o conhecimento do conteúdo, a seleção deles e a sua aplicabilidade, pertinentes para a aprendizagem e também tent ar fugir do ensino como linearidade. O conhecimento est at ístico pode proporcionar ao aluno, que seja capaz de participar de discussões, comunicando de forma efetiva e clara, questionando dados que são apresentados (L7N2), (L9N2).

Os saberes disciplinares derivam das disciplinas, historicamente organizadas pelo campo científico em suas fontes de produção de saber, e constituem o conteúdo a ser ensinado (TARDIF, 2014). Entende-se assim, que os saberes disciplinares podem incluir o letramento, o pensamento e o raciocínio estatístico, pois, para ser letrado estatisticamente é necessário saber utilizar conceitos e procedimentos específicos da Estatística, caracterizando o domínio do conteúdo, necessário aos licenciandos enquanto futuros professores.

Na unidade "Competências estatísticas" esses saberes foram manifestados pelos licenciandos na interpretação de gráficos e tabelas, 
cálculo das medidas de tendência central e dispersão, amostra e estimativa como podem ser vistos nos registros a seguir.

Com a atividade dos peixes os alunos podem entender o que é uma amostra e a estimativa de algo.

Logo abaixo da tabela apresent ou seis questões, $1^{\circ}$ pediu que informasse as variáveis e separa-las em 2 grupos, $2^{\circ}$ que construísse tabelas de distribuição de frequência, $3^{\circ}$ determinar se era possivel calcular a média? Nest a etapa respondi que sim, depois da explicação do professor, descobri que os dois grupos eram as variáveis quantitativas que se subdividem em: variáveis discretas e continuas e as variáveis qualitativas que se subdividem em: variáveis nominais e ordinais (L7MI), (L4N4).

Na perspectiva de Gal (2002), a habilidade para elaborar questões críticas ou analisar criticamente uma informação é um elemento cognitivo do modelo de letramento estatístico, que foi manifestado pelo registro L4M3 ([...] podemos verificar que a maioria dos alunos dessa turma de $3^{\circ}$ ano do Ensino Médio pretende continuar os estudos, mas est ão divididos entre um curso técnico e a universidade, sendo que a maioria deles já trabalha para ajudar em casa ou para ser independente) ao realizar uma investigação estatística sobre as preferências de alunos do Ensino Médio. Percebe-se assim, que "[...] os alunos aprendem mais quando incentivados a discutir, a refletir e a resolver os problemas; e tiram proveito das ocasiões para pôr em prática suas ideias e os conhecimentos do conteúdo[...]" (LOPES, 2013, p. 907).

Portanto, em relação a este conhecimento, houve o desenvolvimento no que se refere ao letramento estatístico, articulado com outros que compõem os saberes da docência, conforme posto por Tardif (2014), por meio da familiaridade com os termos e ideias básicas relacionadas às apresentações gráficas e tabulares, a familiaridade com os termos e ideias básicas relacionadas à Estatística Descritiva, o conhecimento sobre como as conclusões e inferências estatísticas são obtidas (GAL, 2002), como pode ser visto no registro dos licenciandos: 
A pesquisa desenvolvida foi uma experiência construtiva, pois não havíamos realizado pesquisas estatísticas antes, definimos o objetivo da pesquisa, elaboramos as quest ões, coletamos os dados, comunicamos os mesmos por meio de gráficos e tabelas, definimos a medida de tendência central que mais se encaixava aos dados obtidos e concluímos a nossa pesquisa (L4M3), (L9M3).

A investigação estatística contribuiu para que conseguissemos conhecer a realidade do ambiente que estamos inseridos, resolvendo problemas relacionados com o cotidiano, formulando hipóteses e tirando as conclusões (LIM2).

Desta forma, acredita-se que O PEE contribuiu com os saberes disciplinares dos licenciandos ao mobilizarem conhecimentos de Estatística, que, alguns foram aprendidos pela primeira vez e outros (re)elaborados, aproximando assim do que é proposto por Lopes (2013, p. 912), onde um curso de licenciatura em Matemática 'deve possibilitar aos alunos "a apropriação de um conhecimento estatístico que vá além da resolução de problemas, ou seja, deve promover a realização de projetos e atividades de investigação e a problematização de situações diversas; e escolher adequadamente os processos de coleta, representação e análise de dados".

$\mathrm{Na}$ tentativa de contribuir com o desenvolvimento dos saberes disciplinares, assumiu-se uma concepção da Estatística enquanto ciência para análise de dados, articulada com os conceitos da Matemática (LOPES, 2013), ao desenvolver um PEE que permitirá aos futuros professores mobilizarem conceitos e procedimentos estatísticos para analisar, selecionar e produzir materiais didáticos; elaborar propostas de ensino-aprendizagem de Matemática para a educação básica, conforme orientações de Brasil (2001b).

O pensamento estatístico foi desenvolvido tendo em vista que alguns de seus elementos estabelecidos por Wild e Pfannkuch (1999), foram manifestados pelos licenciandos, como por exemplo, a transnumeração e o uso de modelos estatísticos. 
Est a parte da atividade é o que se chama de Transnumeração, que consiste em compreender processos de mudança de representação, ocorrendo quando se muda a forma de observar ou representar os dados. Muito além dessa mudança, seria perceber a melhor forma de representar a situação. Durante todo o processo investigativo, os grupos eram levados a refletir sobre a melhor forma de represent ar os dados (LOM3), (L4N13), (LION13).

Uma das dimensões do pensamento estatístico, o ciclo investigativo, que se refere à forma de como se age e pensa durante uma investigação estatística, foi manifestado conforme o registro L9M3 ([...], definimos o objetivo da pesquisa, elaboramos as questões, coletamos os dados, comunicamos os mesmos por meio de gráficos e tabelas, definimos a medida de tendência central que mais se encaixava aos dados obtidos e concluímos a nossa pesquisa). Tem como objetivo resolver um problema real, geralmente com a intenção de mudar um sistema, (a pesquisa tratava de um assunto interessante, a falta de emprego em minha cidade), e a interpretação dos resultados (concluímos que a cidade não oferece empregos suficientes para as pessoas que moram aqui, prejudicando muitas pessoas).

Diante dos dados apresentados é possível compreender que caso o professor estagiário com renda até um salário mínimo, morando sozinho e morando em casa alugada, não conseguirá manter as despesas da casa somente com o salário que possui (L6M3).

Percebe-se com os excertos L6M3 e L9M3 a contribuição da interpretação dos resultados para o desenvolvimento da comunicação, da opinião e da criticidade, capacidades utilizadas para compreender os resultados de uma investigação estatística (WILD; PFANNKUCH, 1999). Essas capacidades vão ao encontro das competências e elementos cognitivos apresentados por Gal (2002), para o desenvolvimento do letramento estatístico. Portanto, existe uma relação intrínseca entre o letramento, o pensamento e o raciocínio estatístico e que um não tem precedência sobre o outro (CAMPOS, 2007; SILVA, 2007).

Com a investigação estatística proposta foi possível ofertar aos licenciandos, a mobilização dos conhecimentos adquiridos, para escolher 
um tema de pesquisa, definir um problema a ser investido e elaborar conclusões por meio dos dados coletados. Os saberes desenvolvidos nesse ciclo investigativo são consequências da articulação dos diferentes saberes provenientes da discussão das tarefas realizadas e dos textos escolhidos para leituras. Portanto, houve uma valorização da Estatística (minha visão sobre estatística era apenas de aplicar os dados e fórmulas e calcular o que se pedia no exercício, porém hoje esta visão foi mudada, uma vez que foi possivel conhecer a importância de uma atividade de estatística, L6M3, L3M3) e um diálogo com a Matemática (com a transnumeração, no gráfico de setores, por exemplo, é necessário conhecer ou relembrar os conteúdos de porcentagem, ângulos, circunferência e regra de três, articulando assim matemática e estatística, L4N13), pois, espera-se que eles não fiquem dependentes de livros didáticos, consigam organizar e elaborar suas próprias atividades de ensino articulando seus saberes disciplinares.

O PEE proporcionou aos licenciandos decidirem baseados na observação dos dados, a melhor estratégia a seguir e com as tarefas realizadas, como "Simulação de um dado equilibrado" e "Quantos peixes existem em uma lagoa", pensar em uma situação de incerteza, aspectos do raciocínio estatístico. Alguns excertos foram escolhidos para representar 0 desenvolvimento dessa competência conforme as definições sobre os tipos de raciocínio de Garfield (2002).

O raciocínio sobre dados foi desenvolvido no entendimento das diversas formas de representações los dados coletados podem ser representados por meio de gráficos, tabelas, quadros e pictogramas, L6N13, L7N13, L5N13).

O raciocínio sobre representação dos dados na compreensão sobre a melhor forma de representar um conjunto de dados ( a transnumerção pode ser entendida como a possibilidade de mudar a represent ação dos dados com o objetivo de melhorar a compreensão do problema, L4N13, LIONI3, L7N13).

Já o raciocínio sobre medidas estatísticas pode ser vista no entendimento de qual medida é a mais adequada em cada caso (Não 
dava pra calcular a média da cor dos olhos e do gênero, por serem variáveis qualitativas. Somente dava para calcular a média de variáveis quant itativas que foi o caso da alt ura e do peso, L8N4).

Com as tarefas realizadas em sala de aula, o raciocínio sobre incerteza foi evidenciado ao trabalhar com ideias de aleatoriedade e probabilidade para eventos que envolviam incertezas (com o jogo do bingo podíamos relacionar cada rodada com a probabilidade de ter o próximo número e a probabilidade de ganhar o jogo, L9N7, L3N7).

No raciocínio sobre amostras puderam entender a relação entre a amostra e a população ( $\mathrm{Na}$ estimativa populacional tivemos uma experiência com a quantidade de peixes em um rio. Retirávamos amostras, marcávamos os peixes e devolvíamos no pacote, assim, encontrando uma estimativa para a quantidade, L4N7).

De acordo com os registros apresentados, o raciocínio estatístico foi desenvolvido, contribuindo para o letramento e o pensamento estatístico, tendo em vista a relação entre essas três competências, "[...] à medida que um indivíduo apresenta um nível de raciocínio mais avançado [...] e pensa estatisticamente [...], seu nível de letramento estatístico será maior. Ou seja, o nível de letramento estatístico é dependente do raciocínio e pensamento estatísticos" (SILVA, 2007, p. 35).

\section{CONSIDERAÇÕES FINAIS}

No Projeto de Ensino de Estatística os licenciandos desenvolveram e manifestaram saberes disciplinares, considerados necessários para a atuação na Educação Básica, de forma articulada com outros saberes, ao realizarem as tarefas e participarem das discussões em sala de aula, que foram trabalhados de forma contextualizada. A forma escolhida para a abordagem dos conteúdos, sem a ênfase nos procedimentos e técnicas, mas voltado para os conceitos da Estatística, a sua aplicabilidade e importância no contexto educacional e social, mostra um projeto que pode se tornar uma disciplina, estruturada de forma pedagógica. 
Com a análise dos registros dos licenciandos, ressalta-se a dificuldades deles em utilizar alguns conceitos básicos de Estatística, como o de medidas de tendência central, nas tarefas realizadas. No entanto as discussões em sala de aula puderam romper com essa fragilidade e oportunizou 0 desenvolvimento das competências estatísticas, ao possibilitar a leitura e interpretação de gráficos e tabelas, a investigação estatística, onde puderam definir um problema, coletar, interpretar e comunicar dos dados.

Organização, conhecimento e domínio do conteúdo a ser ensinado também foram encontrados nos excertos analisados dos licenciandos, indicando o desenvolvimento dos saberes disciplinares, no qual ressaltaram a importância do conteúdo para a disciplina, os motivos e as razões para ensinar. Desta forma, O PEE contribui com a formação inicial dos professores de Matemática, ao possibilitar o desenvolvimento de saberes necessários à docência, como as Dificuldades/Importância/Motivos/Razões para ensinar Estatística e o entendimento sobre as competências estatísticas.

\section{REFERÊNCIAS}

ALBUQUERQUE, L. C.; GONTIJO, C. H.. A complexidade da formação do professor de matemática e suas implicações para a prática docente. Espaço Pedagógico, v. 20, n. 1, p. 76-87, jan./jun. 2013.

ALMEIDA, C. C. Análise de um instrumento de Letramento Estatístico para o ensino fundamental II. 2010. 107f. Dissertação (Mestrado em Educação Matemática). Universidade Bandeirante de São Paulo, São Paulo, 2010.

ALVES-MAZZOTTI, A. J. Gewandsznajder, F. O método nas ciências naturais e sociais - pesquisa quantitativa e qualitativa. São Paulo: Thomson, 2 ed, 1999.

BRASIL. Ministério da Educação. Conselho Nacional de Educação. Parecer $n^{\circ}$ 9, de 08 de maio de 2001. Diretrizes Curriculares Nacionais para a Formação de Professores da Educação Básica, em nível superior, curso de licenciatura, de graduação plena. Brasília, DF, p. 1-70, 2001 a.

BRASIL. Ministério da Educação. Conselho Nacional de Educação. Parecer $n^{\circ}$ 1.302, de 06 de novembro de $2001 \mathrm{~b}$. Diretrizes Curriculares Nacionais para a os Cursos de Matemática, Bacharelado e Licenciatura. Brasília, DF, p. 1-7, 2001.

BRASIL. Ministério da Educação. Conselho Nacional de Educação. Resolução $n^{\circ} 2$, de 01 de julho de 2015. Diretrizes Curriculares Nacionais para a 
Formação Inicial e Continuada em Nível Superior de Profissionais do Magistério para a Educação Básica. Braślia, DF, p. 1-78, 2015.

BURGESS, T. A. Investigating the nature of teacher knowledge needed and used in teaching statistics. Thesis (Doctorate in Education). Massey University, Palmerston North, Nova Zelândia, 2007. A cesso em 05 jun. 2017.

CAMPOS, C. R. A Educação estatística: uma investigação acerca dos aspectos relevantes à didática da estatística em cursos de graduação. 2007. Tese (Doutorado em Educação). Universidade Estadual Paulista, Rio Claro (SP), 2007.

CAMPOS, C. R; et al. Educação Estatística no Contexto da Educação Crítica. Bolema, Rio Claro (SP), v. 24, n. 39, p. 473-494, ago. 2011.

CARVALHO, A.M. P.; GIL-PÉREZ, D. Formação de professores de ciências. 8.ed. São Paulo: Cortez, 2006.

CORDANI, L. K. Estatística para todos. In:II Bienal da Sociedade Brasileira de Matemática, 2004, Salvador. Anais... Salvador: SBM, 2004.

COSTA, A. A.; NACARATO, A. M. A Estocástica na Formação do Professor de Matemática: percepções de professores e de formadores. Bolema, Rio Claro (SP), v. 24, n. 39, p. 367-386, 2011.

COSTA, W. N. G.; PAMPLONA, A.. S. Entrecruzando Fronteiras: a Educação Estatística na formação de Professores de Matemática. Bolema, Rio Claro (SP), v. 24, n. 40, p. 897-911, dez. 2011.

COUTINHO, C. Q. S.; SILVA, M. J. F..; ALMOULOUD, S. A. Desenvolvimento do pensamento estatístico e sua articulação com a mobilização de registros de representação semiótica. Bolema, Rio Claro (SP), v. 24, n. 39, p. 495-514, ago. 2011.

\section{DAMIN, W. A Educação Estatística e a formação de professores de}

Matemática: contribuições de um projeto para a constituição dos saberes docentes. 2018. 149. Tese (Doutorado em Ensino de Ciência e Tecnologia) Universidade Tecnológica Federal do Paraná. Ponta Grossa, 2018.

ESTEVAM, E. J. G. Práticas de uma Comunidade de Professores que ensinam Matemática e o Desenvolvimento Profissional em Educação Estatística. 2015. 189 f. Tese (Doutorado em Ensino de Ciências e Educação Matemática). Universidade Estadual de Londrina. Londrina, 2015.

GAL, I. Adult's statistical literacy. Meanings, components, responsibilities. International Statistical Review, 70(1), 1-25, 2002.

GARFIELD, J. The challenge of developing statistical reasoning. Journal of Statistics Education, v. 10, n. 3, 2002. 
LOPES, C. A. E. A probabilidade e a estatística no ensino fundamental: uma análise curricular. 1998. 139 f. Dissert ação (Mestrado em Educação). Faculdade de Educação, Universidade Estadual de Campinas. Campinas, 1998.

LOPES, C. A. E. Educação Estatística no Curso de Licenciatura em Matemática. Bolema, Rio Claro (SP), v. 27, n. 47, p. 901-915, dez. 2013.

LOPES, J. M.; CORRAL, R. S.; RESENDE, J. S. O ensino dos conceitos de média, mediana e moda através de um jogo de cartas. In: PROFMAT 2011 Encontro Anual de Professores de Matemática, 201 1, Lisboa. Anais... Lisboa: APM, 2011.

MARTINS, M. E.; PONTE, J. P. Organização e tratamento de dados. Lisboa: MEDGIDC, 2011.

MIZUKAMI, M. G.; REALI, A. M. M.R.; REYES, C. R.; MARTUCCI, E. M.; LIMA, F. L.; TANCREDI, R. M.; MELLO, R. R. Escola e aprendizagem da docência: processos de investigação e formação. São Carlos: Edufscar, 2002.

MIZUKAMI, M. G. N. A prendizagem da docência: algumas contribuições de Lee S. Shulman. Revista Educação. Santa Maria, v. 29, n. 2, p. 33-49, dez. 2004.

MORAES, R.; GALIAZZI, M. C. Análise textual discursiva. Ijuí: Unijuí, 2007. 224 p.

PARANÁ. Secretaria de Estado da Educação. Diretrizes curriculares da educação básica: Matemática. Paraná: SEED/DEB, 2008.

PEREIRA, R.S. G. A Educação a Distância e a formação continuada de professores de Matemática: contribuições de um contexto formativo para a base de conhecimento docente. Tese (Doutorado em Educação).

Faculdade de Ciências e Tecnologia, Universidade Estadual Paulista "Júlio de Mesquit a Filho". Presidente Prudente/SP, 2015.

ROLDÃO, M. C. Função docente: natureza e construção do conhecimento profissional. Revista Brasileira de Educação. São Paulo (SP), v. 12 n. 34, p. 94103, 2007.

SILVA, C. B. Pensamento estatístico e raciocínio sobre variação: um estudo com professores de Matemática. Tese (Doutorado em Educação Matemática). Pontifícia Universidade Católica. São Paulo, 2007.

SNEE, R. D. Statistical thinking and its contribution to total quality. The American Statistician, v. 44, n. 2, p. 116-121, 1990.

SOUZA, L. O. O desenvolvimento profissional de professores em estatística: um projeto Multi-dimensional de formação colaborativa. Tese (Doutorado em Ensino de Ciências e Matemática). Universidade Cruzeiro do Sul, São Paulo, 2013. 
TARDIF, M. Saberes docentes e formação profissional. 17. ed. Petrópolis, RJ: Vozes, 2014.

WILD, C.; PFANNKUCH, M. Statistical thinking in empirical enquiry. nternacional Statistical Review. V. 67, n. 3, p. 223-265, 1999.

Recebido em: 21 de março de 2018. Aprovado em: 20 de dezembro de 2018. 